Supplement of Atmos. Chem. Phys., 19, 10129-10160, 2019

https://doi.org/10.5194/acp-19-10129-2019-supplement

(c) Author(s) 2019. This work is distributed under

the Creative Commons Attribution 4.0 License.

(c) (i)

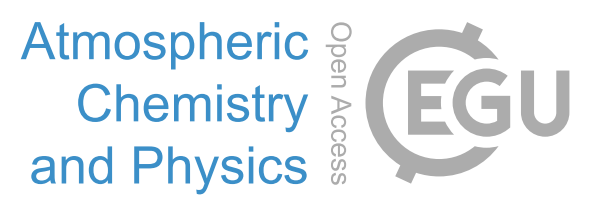

Supplement of

\title{
Transport of Po Valley aerosol pollution to the northwestern Alps - Part 2: Long-term impact on air quality
}

\section{Henri Diémoz et al.}

Correspondence to: Henri Diémoz (h.diemoz@arpa.vda.it)

The copyright of individual parts of the supplement might differ from the CC BY 4.0 License. 


\section{S1 Climatology (2015-2017) of PM vertical profiles}

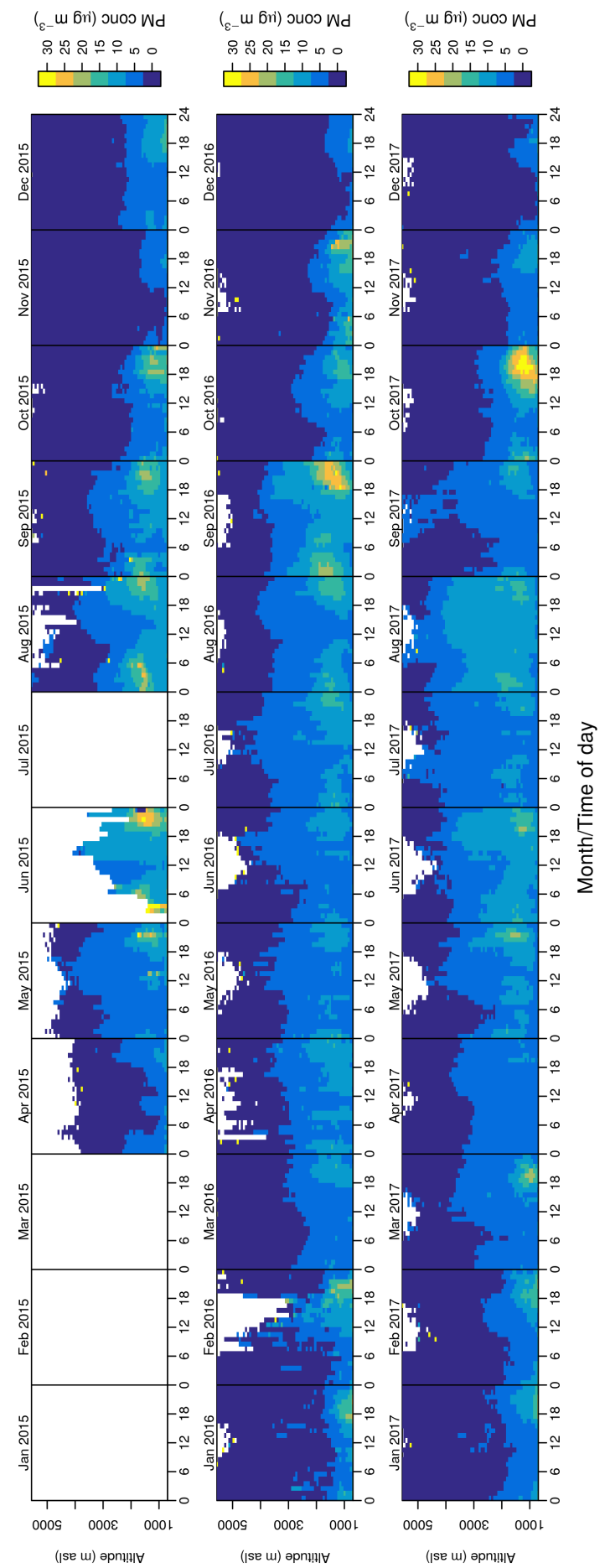

Figure S1: Monthly averages of the hourly PM mass concentration vertical profiles retrieved by the ALC in AostaSaint-Christophe (2015-2017). Points with insufficient statistics are not plotted (white areas, cf. main text). 


\section{S2 Details about the fitting algorithm of the ALC-identified aerosol layers}

To quantitatively explore the spatial and temporal characteristics of the ALC-detected aerosol layer over the long term, we developed an automated procedure which:

1. takes into consideration each day with a valid classification (types A to F) as described in Sect. 4.1 and visualised in Fig. 2 of the main text;

2. filters out the clouds according to the ALC cloud mask (Lufft, 2016) complemented by a temporal variability criterion (data are rejected if standard deviation of the profile-integrated aerosol backscatter $>2 \cdot 10^{-4} \mathrm{sr}^{-1}$ during a 5-minutes time window);

3. selects the space-time region where $\mathrm{SR} \geq 3$ (chosen as the boundary between the advected aerosol layer and the "clean" air);

4. fits the envelope of the aerosol loaded region, as a function of time and altitude, with a straight line (case $\mathrm{F}$ ) or a sigmoid curve (cases $\mathrm{C}-\mathrm{E}$ ) to take into account the arrival and persistence of the aerosol layer at different altitudes. Figure 2 (main text) shows some examples of this interpolation as dashed lines on top of the contour plots. Indeed, thermally-driven flows usually start at ground level and then propagate to higher altitudes (Egger et al., 2000).

The sigmoid curve at point 4 is based on a logistic function, defining the altitude of the layer $(h)$ as a function of time $(t)$ :

$$
h(t)=\frac{A+B}{2}-\frac{A-B}{2} \operatorname{erf}\left(\frac{t-t_{0}}{\Delta t}\right)
$$

where $A$ and $B$ are the minimum/maximum altitudes of the layer, $t_{0}$ is the time when the altitude of the layer reaches half of the final altitude and $\Delta t$ is the duration of the transition. 
S3 Supplementary information about impact of advections on surface air quality
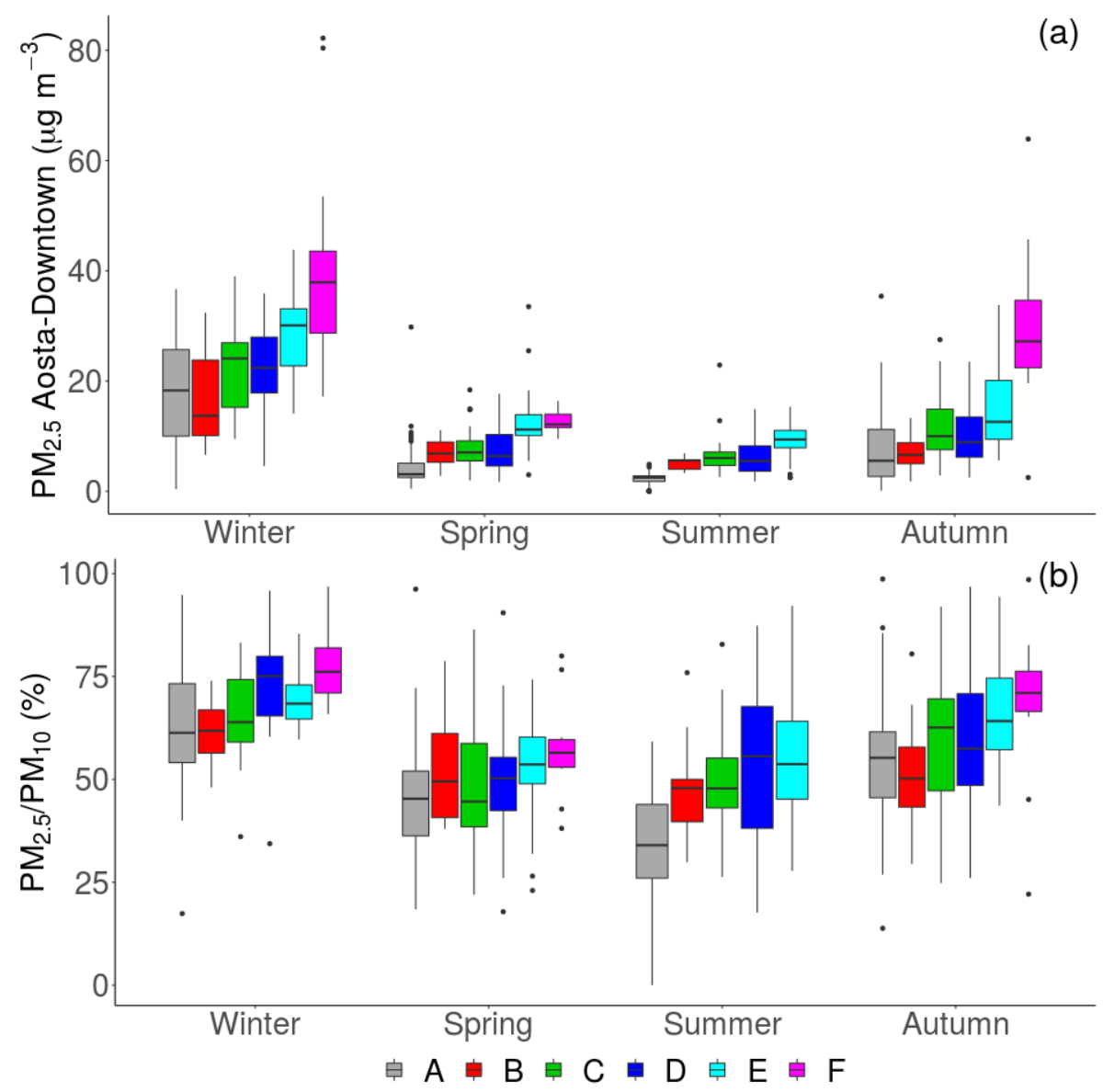

Figure S2: Average (2015-2017) $\mathrm{PM}_{2.5}$ surface concentration (a) and $\mathrm{PM}_{2.5} / \mathrm{PM}_{10}$ ratio (b) in Aosta-Downtown. 


\section{S4 Surface PM composition and sources from Positive Matrix Factorisation of chemical analyses}

Using the anion/cation series (PMF-dataset a), the best decomposition was obtained with five modes (Fig. 11 in the main text, pink bars, and Fig. S3, $Q / Q_{e x p}=1.9, \mathrm{PM}_{10}$ reconstructed with $\mathrm{R}^{2}=0.85$ ), and namely:

1. winter road salting and subsequent resuspension by vehicles (high percentages of $\mathrm{Na}^{+}$and $\mathrm{Cl}^{-}$ions);

2. soil $\left(\mathrm{Ca}^{2+}\right.$ and $\left.\mathrm{Mg}^{2+}\right)$;

3. combustion processes (mainly from traffic and heating, with large contributions of nitrogen oxides and PAH);

4. nitrate-rich secondary aerosol (prevalence of nitrate and ammonium);

5. sulfate-rich secondary aerosol (large percentage of sulfate and ammonium).

Most part of the species unaccounted by the chemical analysis is included in the traffic and heating mode and can be easily attributed to the carbon mass (as confirmed by the results from PMF-dataset b, see below). The remaining part of the unknown fraction is found in the sulfate-rich factor. Presence of potassium in several modes reflects its ubiquitous origin (biomass burning, soil dust, use of fertilisers, industry; Aiken et al. (2010); Urban et al. (2012)). The robustness of the factorisation was tested using a) the displacement method (DISP, negligible $\mathrm{d} Q_{\max }$ and no swaps), b) the bootstrap method (BS, 100 runs, road salting factor well mapped $97 \%$ of the times probably due to its presence only in winter and its intrinsic connection with traffic resuspension, and other factors well mapped $100 \%$ of the times) and c) the bootstrap/displacement method (BS-DISP, 97\% of cases accepted, 2 swaps out of 100 runs), as explained by Paatero et al. (2014).

Similar factors were found for PMF-dataset b (Fig. 11, green bars, and Fig. S4, $Q / Q_{\text {exp }}=2.3, \mathrm{R}^{2}=0.85$ for $\mathrm{PM}_{10}$ ), in which the measured carbon species replace the unknown PM fraction missing in the first dataset. In this second case, the DISP test resulted into negligible $\mathrm{d} Q_{\max }$ and no swaps. The BS test highlights that the road salting factor is sometimes (11\%) mapped as the nitrate-rich one, likely due to the maximum effectiveness of both modes in winter, while the other factors are well mapped $100 \%$ of the times. Only $76 \%$ of the cases were accepted by the BS-DISP test, probably owing to the reduced length of this dataset (Sect. 3.3).

Seven factors were conversely required for PMF-dataset c (Fig. 11, blue bars, and Fig. S5, with $Q / Q_{\text {exp }}=3.8$, $\mathrm{R}^{2}=0.92$ for $\mathrm{PM}_{10}$ ). In fact, the inclusion of metals allowed identification of two industrial contributions (reaching $20 \%$ ), mainly from the local steel mill, halving the traffic and heating one with respect to the previous datasets. The first industrial source includes the vast majority of industrial metal tracers $(\mathrm{Cr}, \mathrm{Mn}, \mathrm{Ni}, \mathrm{Mo}$, etc.), while the second one includes $\mathrm{Cd}$ and $\mathrm{Pb}$, mostly due to a specific exceedance episode in 2017 from impurities in the feedstock. Again, the unknown PM fraction behaves like the carbonaceous aerosol of PMF-dataset $\mathrm{b}$, as expected. Negligible $\mathrm{d} Q_{\max }$ and no swaps were found with the DISP test. Some swaps were detected by the BS test ( $25 \%$ of the times) especially between the traffic and heating factor and the industry factor, meaning that a sharp separation of the two modes is a difficult task even using metal analyses. $82 \%$ of the cases were accepted by the BS-DISP test.

In Fig. S6, we report the contributions of all factors over the year, this further revealing that the largest differences between the datasets occur in January and December 2017 for the traffic and heating factor. An overall consistency is however found for the seasonal dependence of the factors contribution, with some sources having a pronounced seasonal dependence (e.g. road salting, traffic and heating, and nitrate-rich are dominant in winter, while the sulfate-rich one is more abundant in the mild season). On a weekly scale (not shown), half of the factors show statistically significant workday/weekend differences (traffic and heating, industry and soil, the latter probably due to some resuspension by traffic and by industrial processes; significance was proven by the p-values $<0.05$ from the one-tailed Mann-Whitney test) while the others do not show any statistically significant weekly cycle (road salting, nitrate-rich and sulfate-rich, with p-values $>0.05)$. 

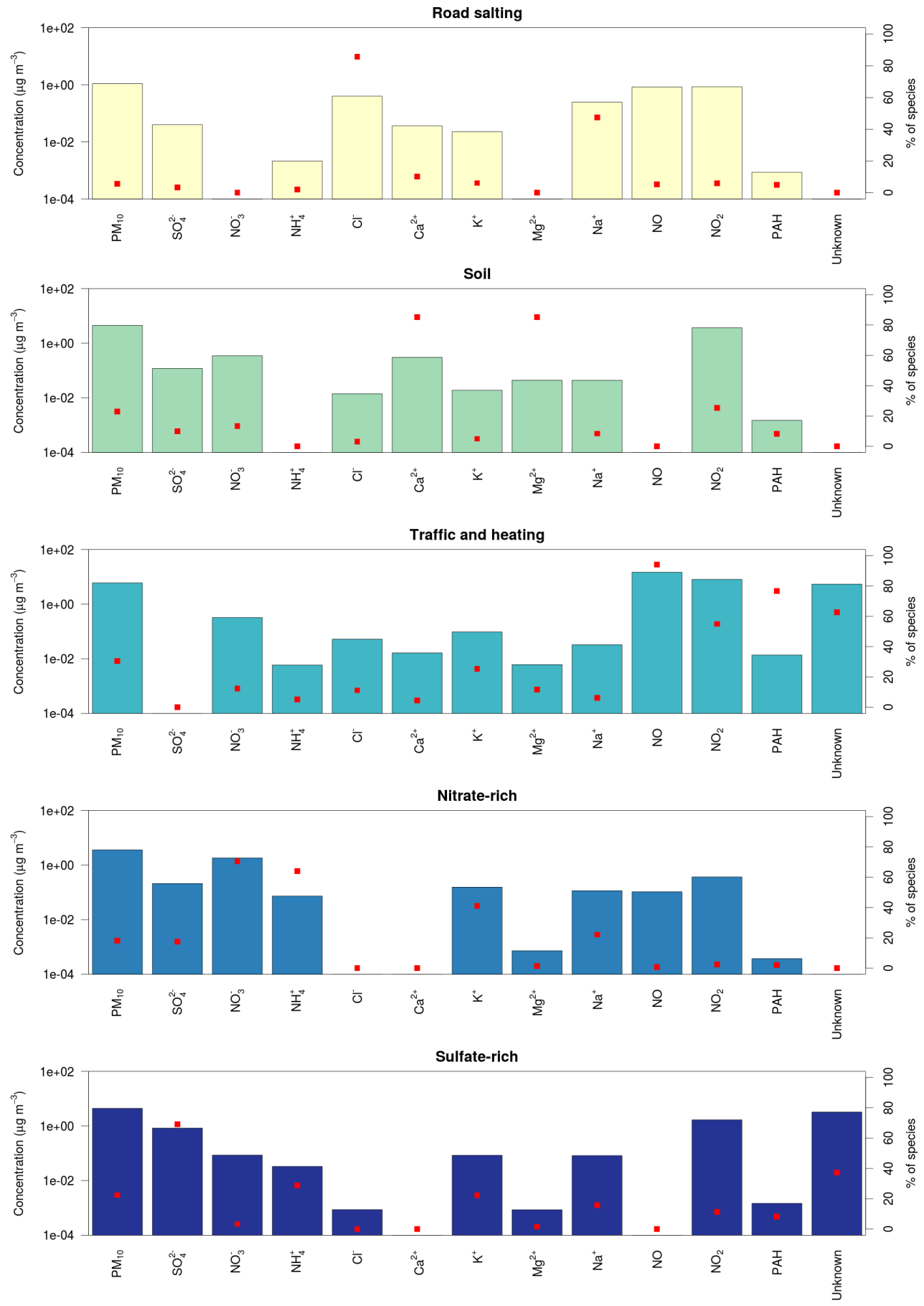

Figure S3: Factor profiles from PMF of the anion/cation series (PMF-dataset a). Coloured bars (left axis) represent absolute concentrations (in $\mu \mathrm{g} \mathrm{m}^{-3}$ for all species, with the exception of $\mathrm{PAH}$, expressed in $\mathrm{ng} \mathrm{m}^{-3}$ ), red points (right axis) mark the percentage contribution to each mode of the total for each species. 

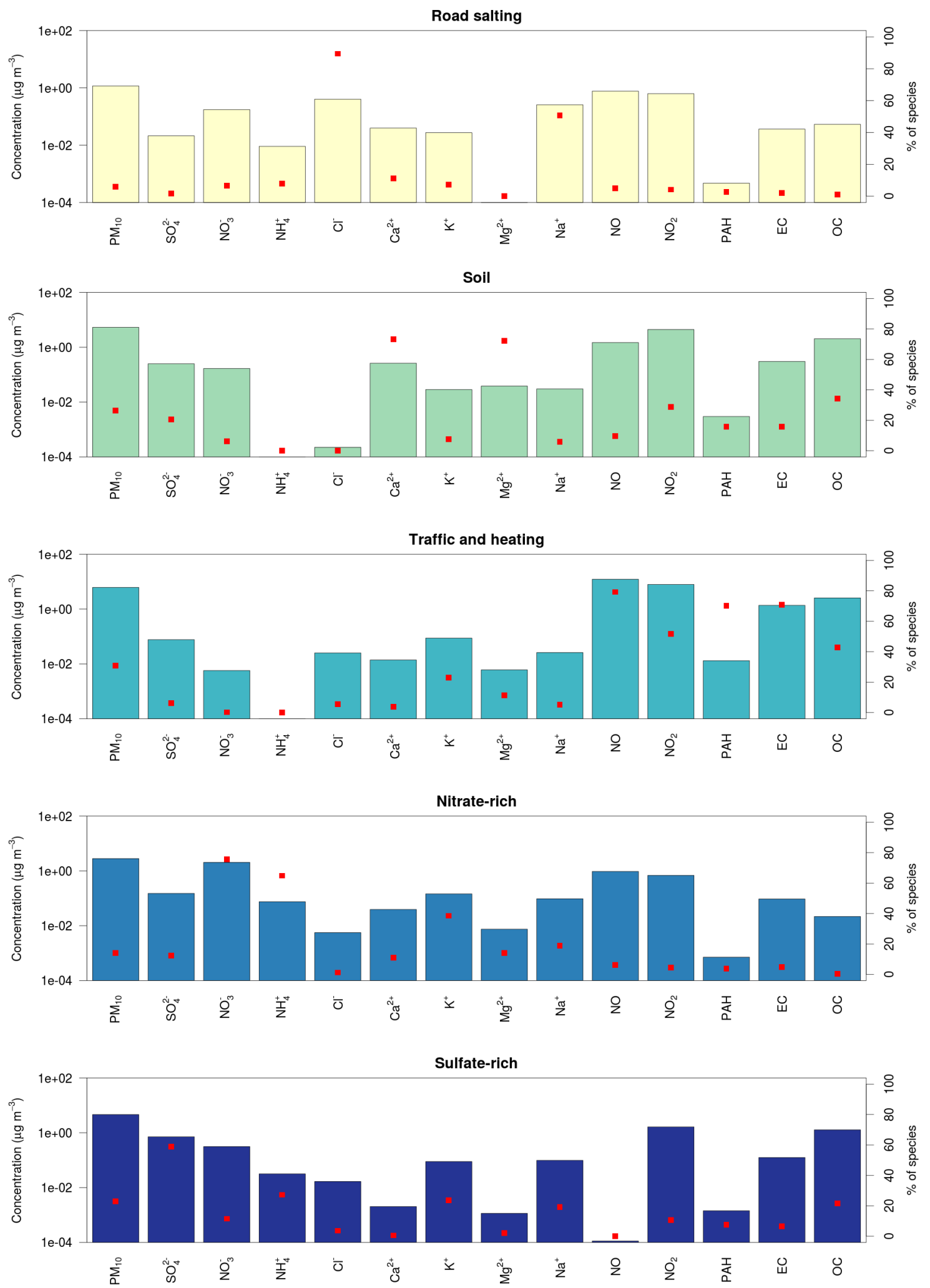

Figure S4: Factor profiles from PMF of the subset with anion/cation and EC/OC analyses (PMF-dataset b). 

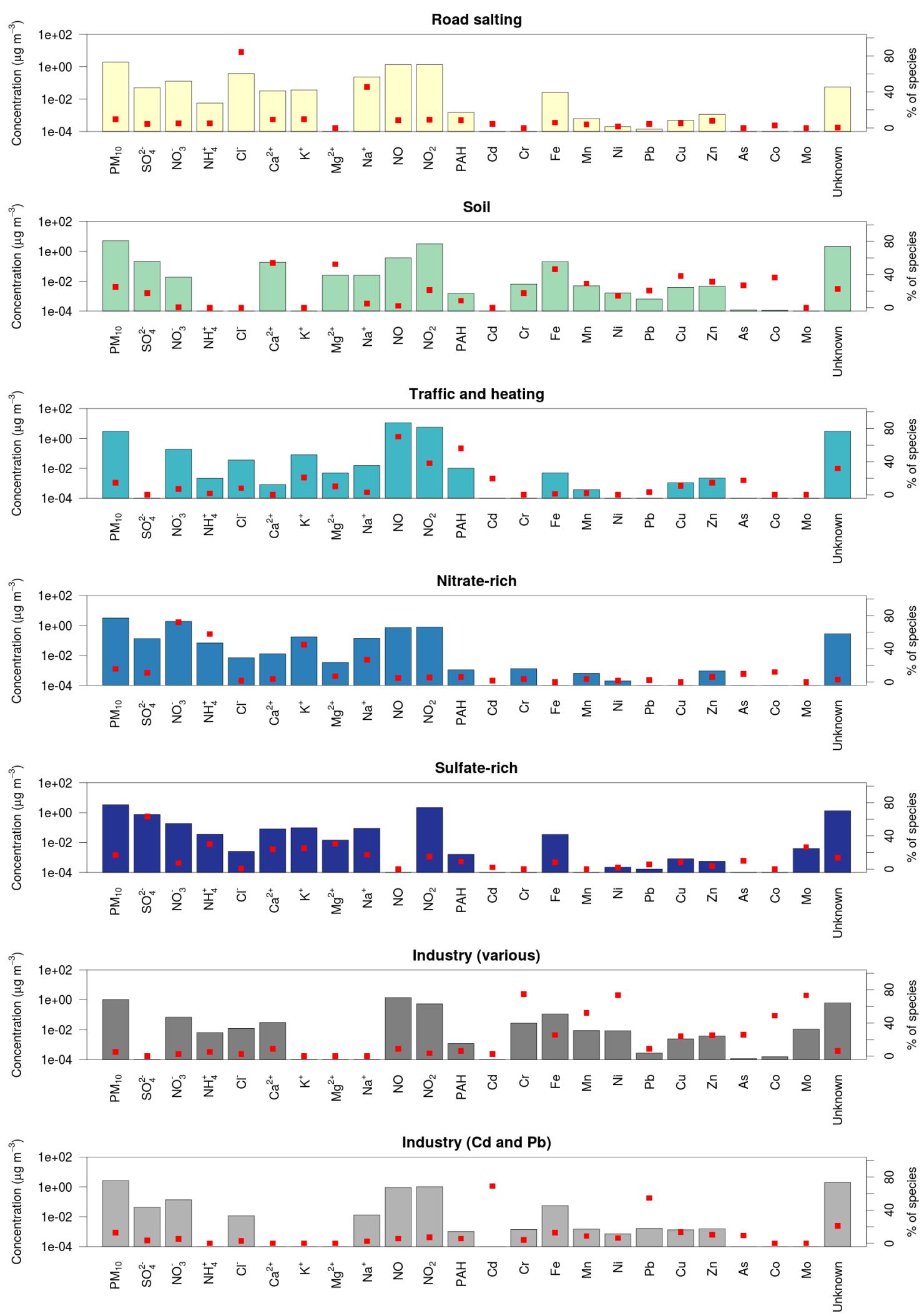

Figure S5: Factor profiles from non-negative matrix factorisation of the subset with anion/cation and metals analyses (PMF-dataset c). 

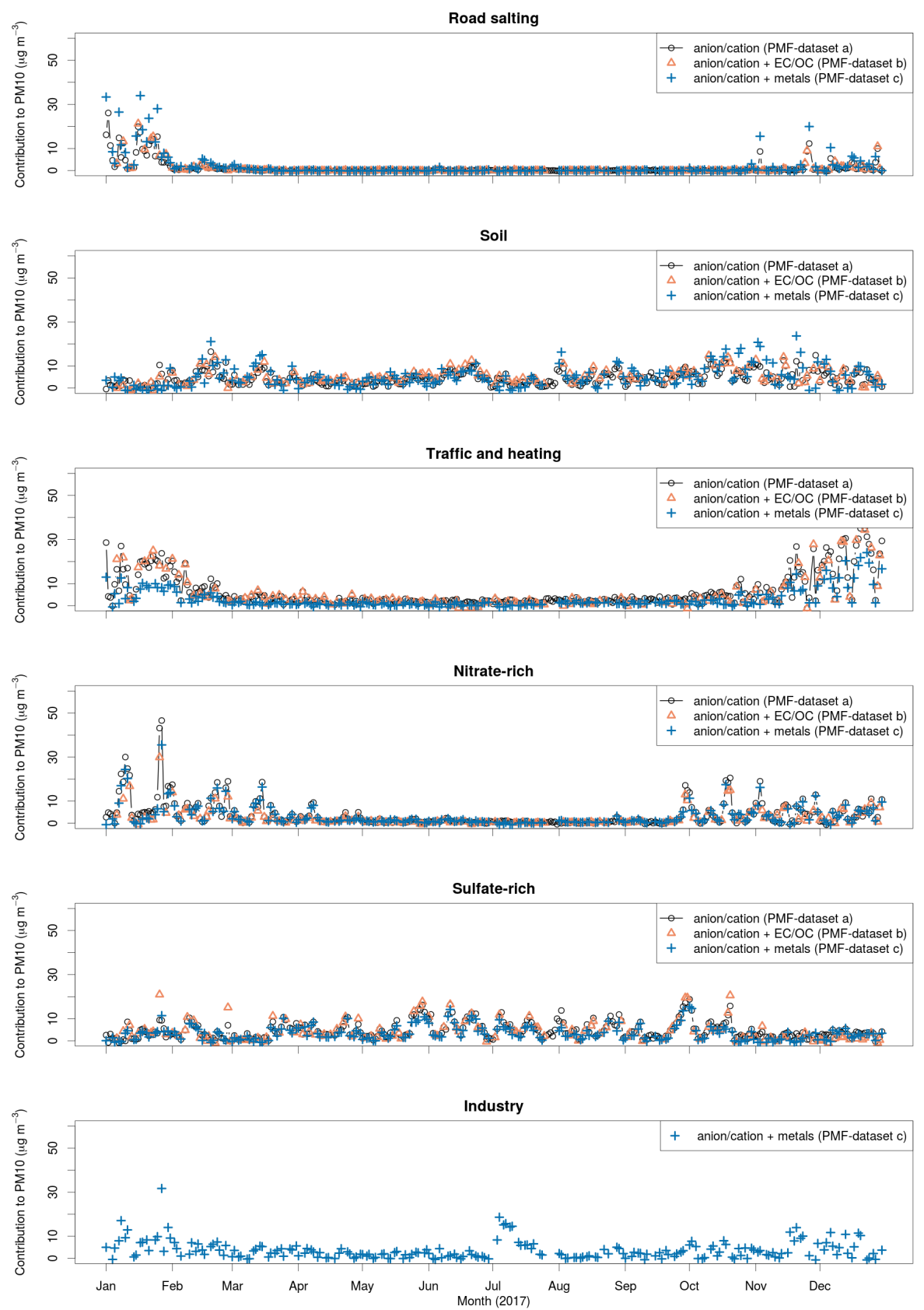

Figure S6: Factor contributions, in terms of $\mu \mathrm{g} \mathrm{m}{ }^{-3}$, to the $\mathrm{PM}_{10}$ mass for the three datasets. The industry contributions in the lowest panel are calculated as a sum of the two industrial modes from the PMF analysis with metals. 


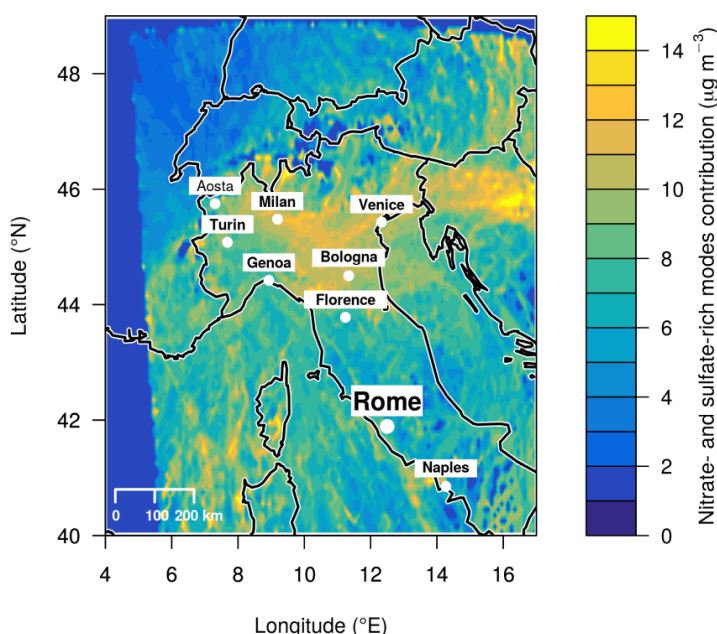

(a)

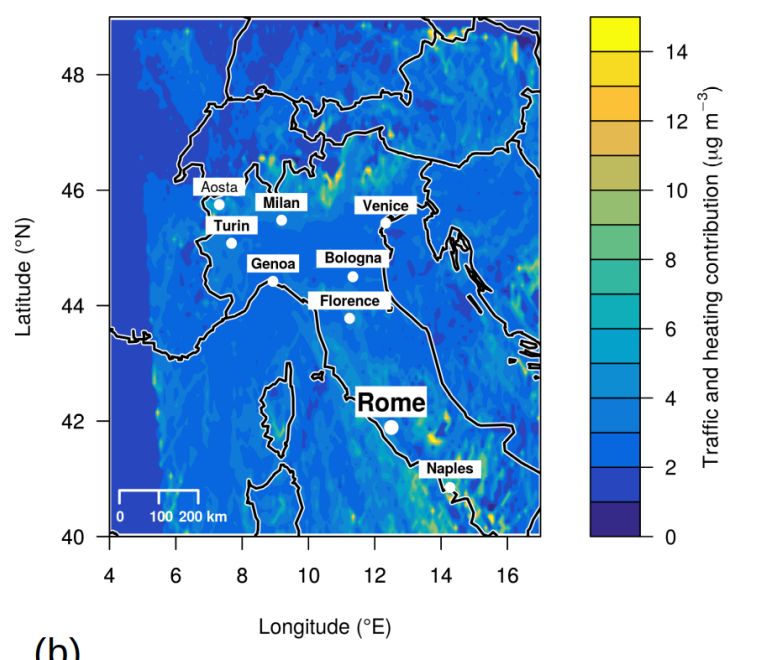

(b)

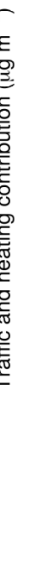

Figure S7: Same as Fig. 13 in the main paper, but without any weighting applied to the backtrajectory cells. (a) Output of the Concentration Field TSM, using the sum of the contributions from PMF nitrate- and sulfate-rich modes as concentration variable at the receptor (Aosta-Downtown). (b) CF based on the traffic and heating mode from PMF. Trajectories are cut at the borders of the COSMO-I2 domain. 


\section{S5 Other pollutants at the surface}

Since PM-related pollution is the focus of this work, we have mainly explored the influence of the described phenomenon on aerosol concentrations and properties in the main paper. Here we provide just a hint to show that the described phenomenon is expected to also impact ground-level gas-phase pollutants concentrations. Nitrogen oxides were selected for testing purposes, since they are typical compounds mainly associated with human activities in urbanised areas (combustion processes) and are legislated by EU air quality regulations (EU Commission, 2008). In the main paper, we already showed that the overall concentration of nitrogen oxides does not relevantly change during advection episodes (Fig. 8b). We now analyse the partitioning between $\mathrm{NO}$ and $\mathrm{NO}_{2}$. In particular, since $\mathrm{NO}$ is quickly oxidised after emission to form $\mathrm{NO}_{2}$, the $\mathrm{NO}_{\mathrm{x}} / \mathrm{NO}$ ratio was chosen as a good indicator of the distance from the emission sources and, more generally, of the oxidative capacity of the atmosphere (e.g., Cugerone et al., 2018, and references therein). In fact, aim of the present analysis is to prove that transport in the Alpine region from the Po basin adds aged pollutants to the locally emitted ones. To this purpose, only the warm season (May-September 2017) is considered to avoid a disproportionate impact by the local wintertime emission sources. Figure S8a, showing for ease of clarity a subset of the series, reveals a good correspondence, on the daily time scale, between the $\mathrm{NO}_{\mathrm{x}} / \mathrm{NO}$ ratio and the relative concentration of sulfates in $\mathrm{PM}_{10}$. The latter was chosen as a tracer of summertime aerosol advections, as demonstrated in Sect. 4.3.2. Only slight discrepancies can be noticed, probably owing to the fact that gaseous and aerosol species are transported in different ways and, above all, because the $\mathrm{NO}_{\mathrm{x}} / \mathrm{NO}$ equilibrium is much impacted by the daily photochemistry. To prove that the correspondence with the ALC classes is also valid on a statistical (average) level, a boxplot of the $\mathrm{NO}_{\mathrm{x}} / \mathrm{NO}$ ratio is plotted in Fig. S8b. Further investigations on this topic are scheduled for the future.
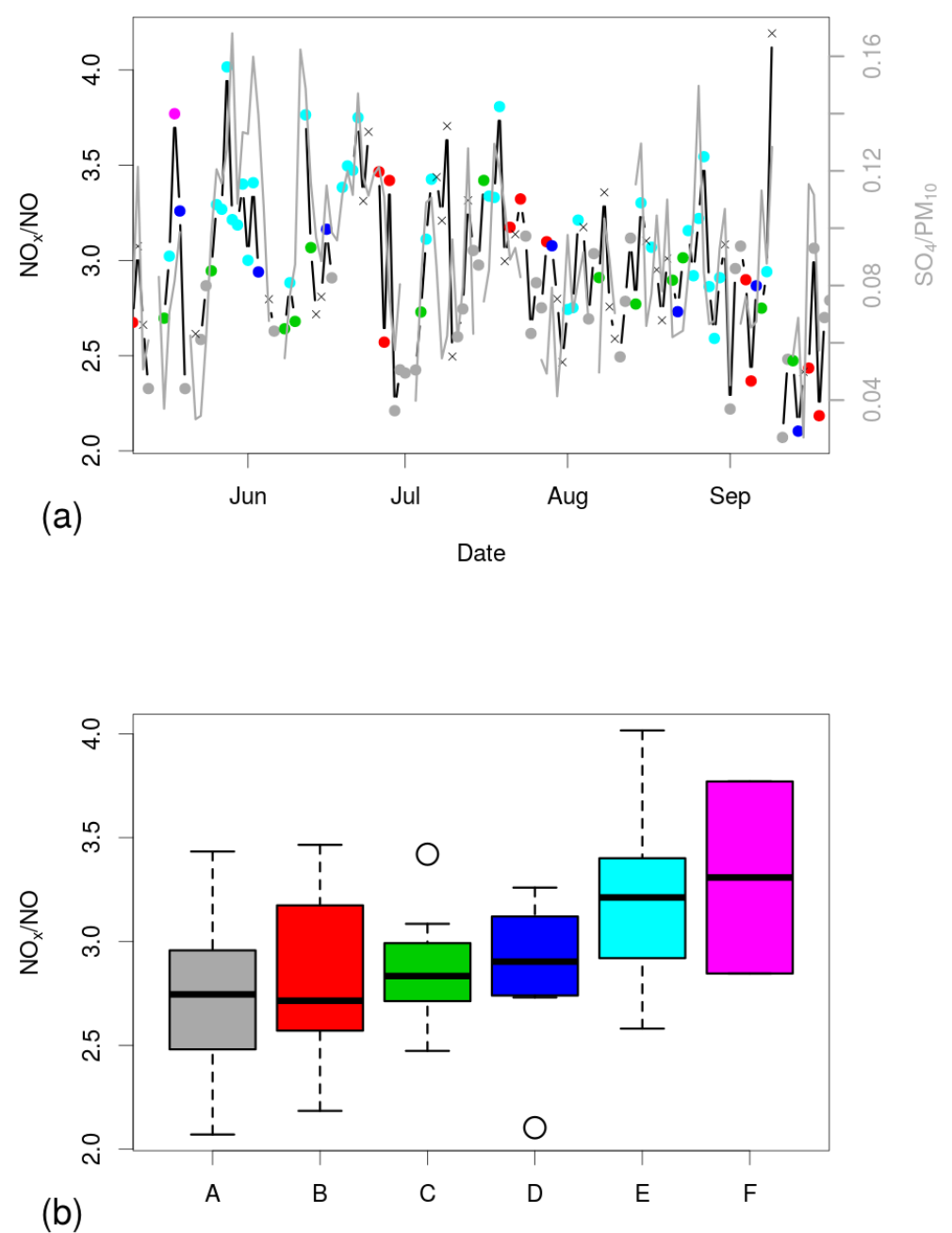

Figure S8: (a) Example subset of the $\mathrm{NO}_{\mathrm{x}} / \mathrm{NO}$ ratio during the warm period (2017, black line and coloured markers, left scale) and fraction of sulfate in $\mathrm{PM}_{10}$ (grey line, right scale), as a proxy of the advections in the warm season; (b) boxplot of $\mathrm{NO}_{\mathrm{x}} / \mathrm{NO}$ ratio, calculated on a daily basis, as a function of the ALC classes. The same colour codes are used in both figures, with unclassified data represented with crosses. 


\section{S6 Supporting material on particle size distributions}

To avoid biases due to the uneven distribution of the ALC day types throughout the year (Fig. 3 in the paper), we split the analysis into the four seasons. The resulting PSDs, averaged for day types (ALC-classification) and seasons, are presented in Fig. S9, showing that the particle load, especially in the fine $(<1 \mu \mathrm{m})$ fraction, increases with the strength and duration of the advection. On the other hand, this is not generally true for the largest sizes, for which the local contribution can be relevant (see winter case). Furthermore, the OPC data reveal that the average particle diameter of the fine mode is larger in autumn/winter compared to spring/summer. This seasonal behaviour is connected to the aerosol chemical characteristics, as explained in the main text (Sect. 4.3.3).

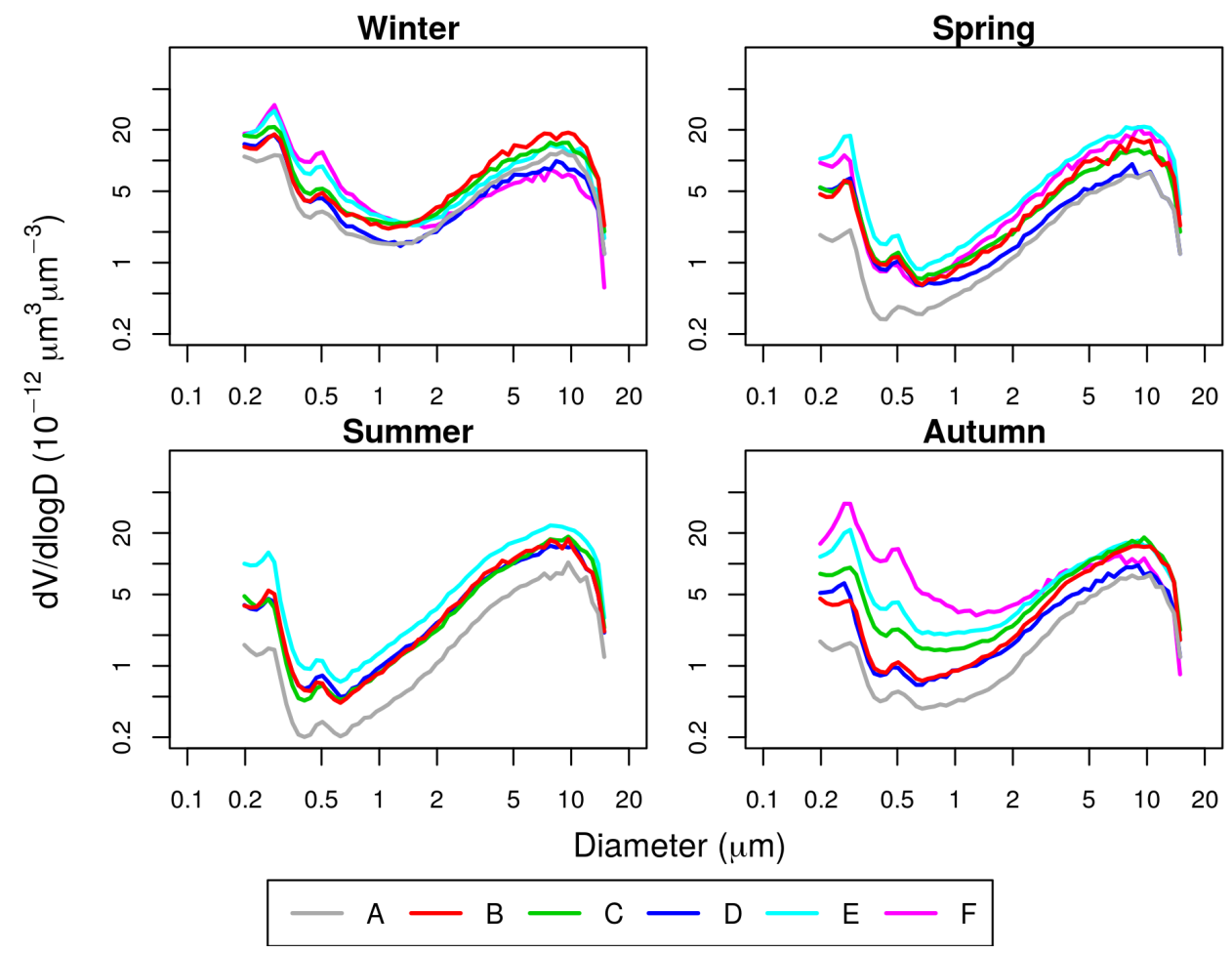

Figure S9: Average particle volume distributions measured by the OPC at Aosta-Saint-Christophe, weighted by a typical cut-off efficiency of $\mathrm{PM}_{10}$ sampling head. 
(a)

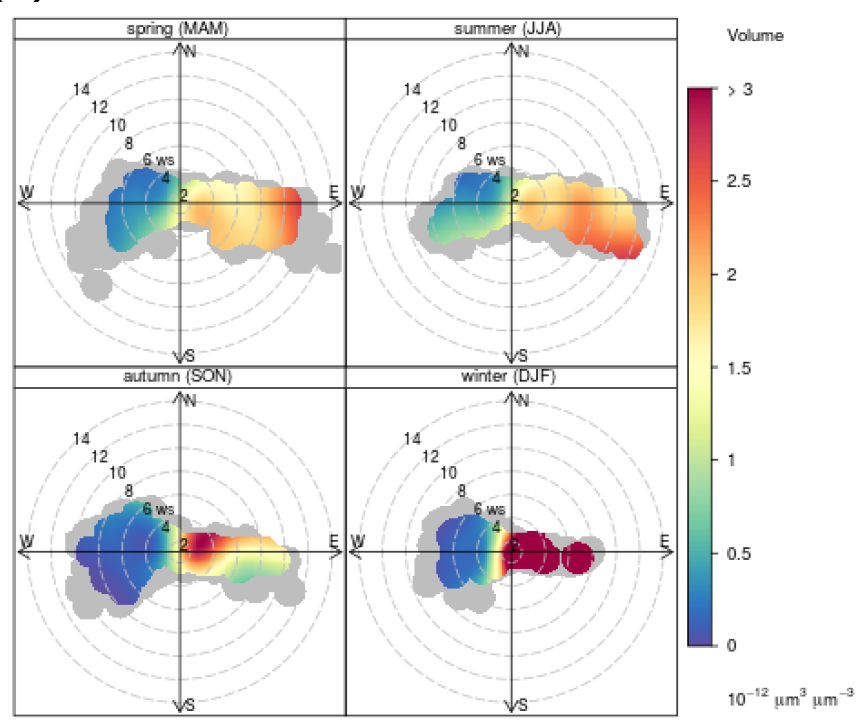

(b) Contribution to volume from PMF mode centered at $0.5 \mu \mathrm{m}$

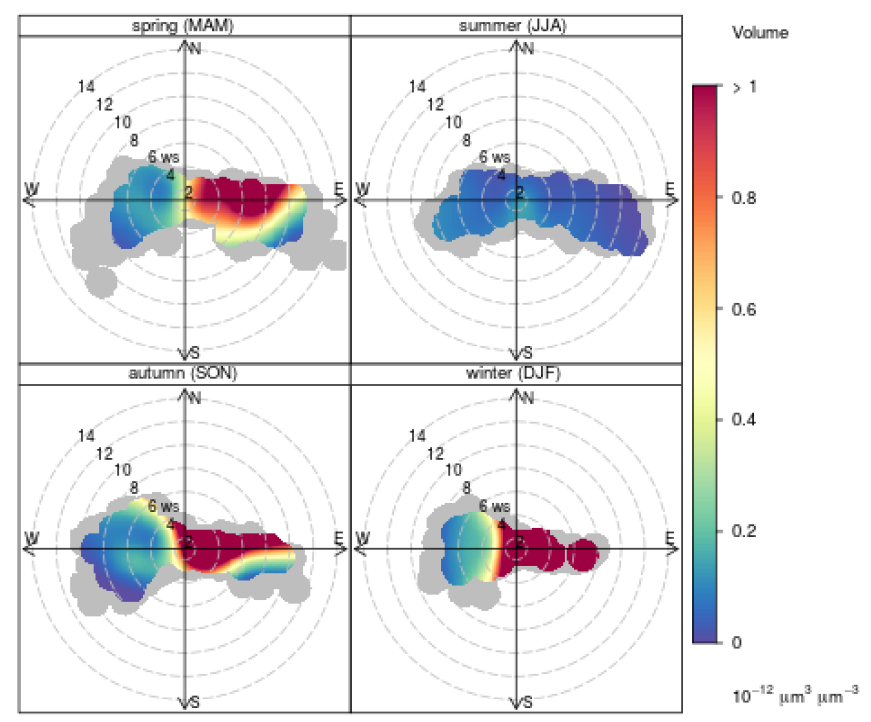

(C) Contribution to volume from PMF mode centered at $2 \mu \mathrm{m}$

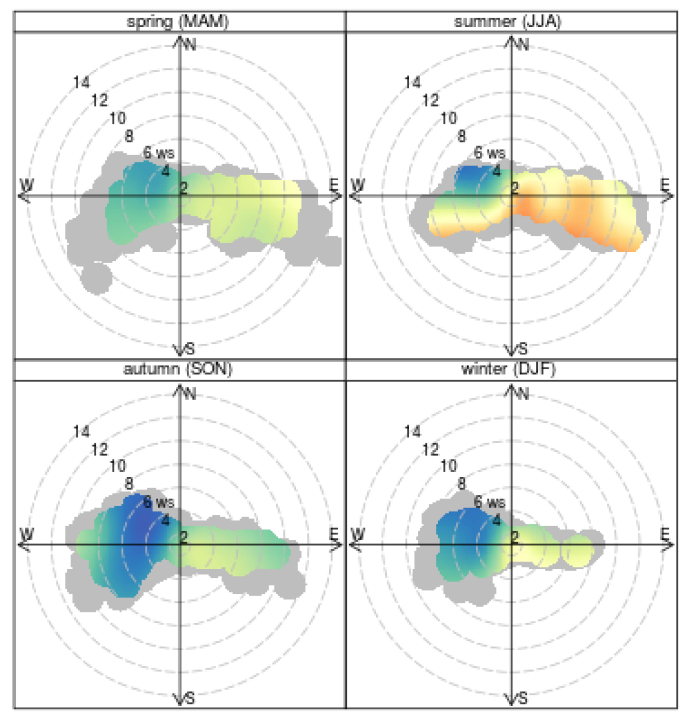

Volume

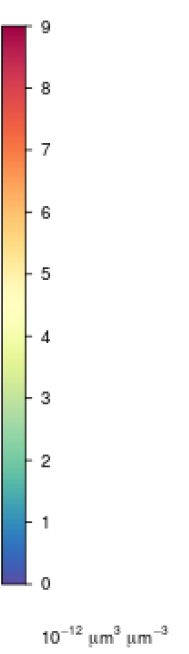

(d) Contribution to volume from PMF mode centered at $10 \mu \mathrm{m}$

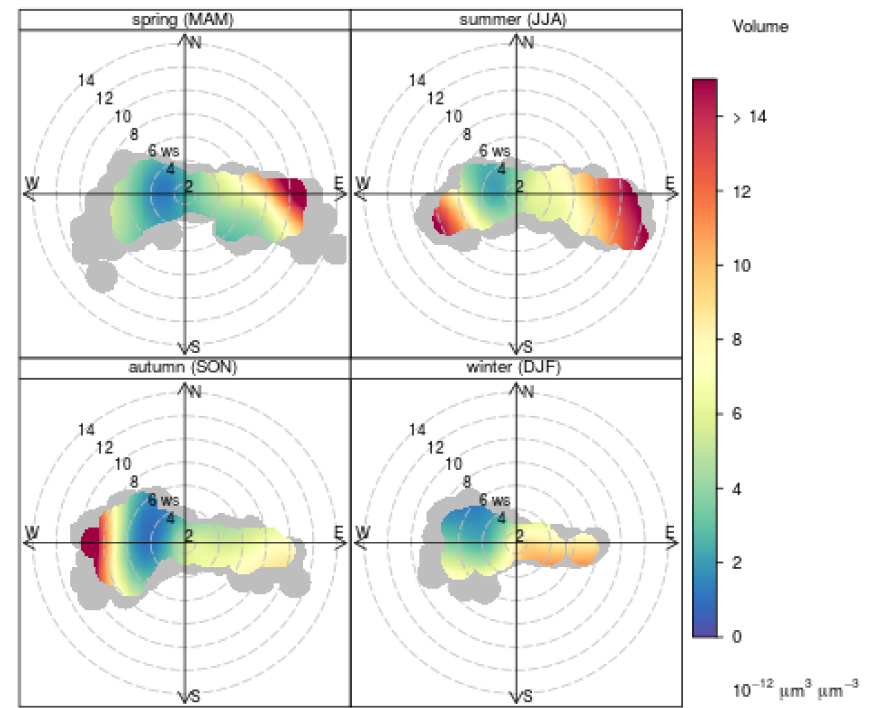

Figure S10: Correlation between the volume contributed by each mode of the size-PMF (colour scale) and wind velocity (distance from the centre of polar plot represents speed and angle represents wind provenance direction). The four cases refer to the modes centred at $0.2,0.5,2$ and $10 \mu \mathrm{m}$. The most interesting features visible in this plot are the following: 1) maximum aerosol volumes are associated to easterly winds; 2$)$ in the warm season, presence of large particles (2 and $10 \mu \mathrm{m}$ size-PMF modes) are additionally noticeable from the south (national road) and west (carpentry, this latter only for high wind speeds), likely due to resuspension effects; 3 ) particles corresponding to the $0.5 \mu \mathrm{m}$ size-PMF mode are almost missing during summer. 

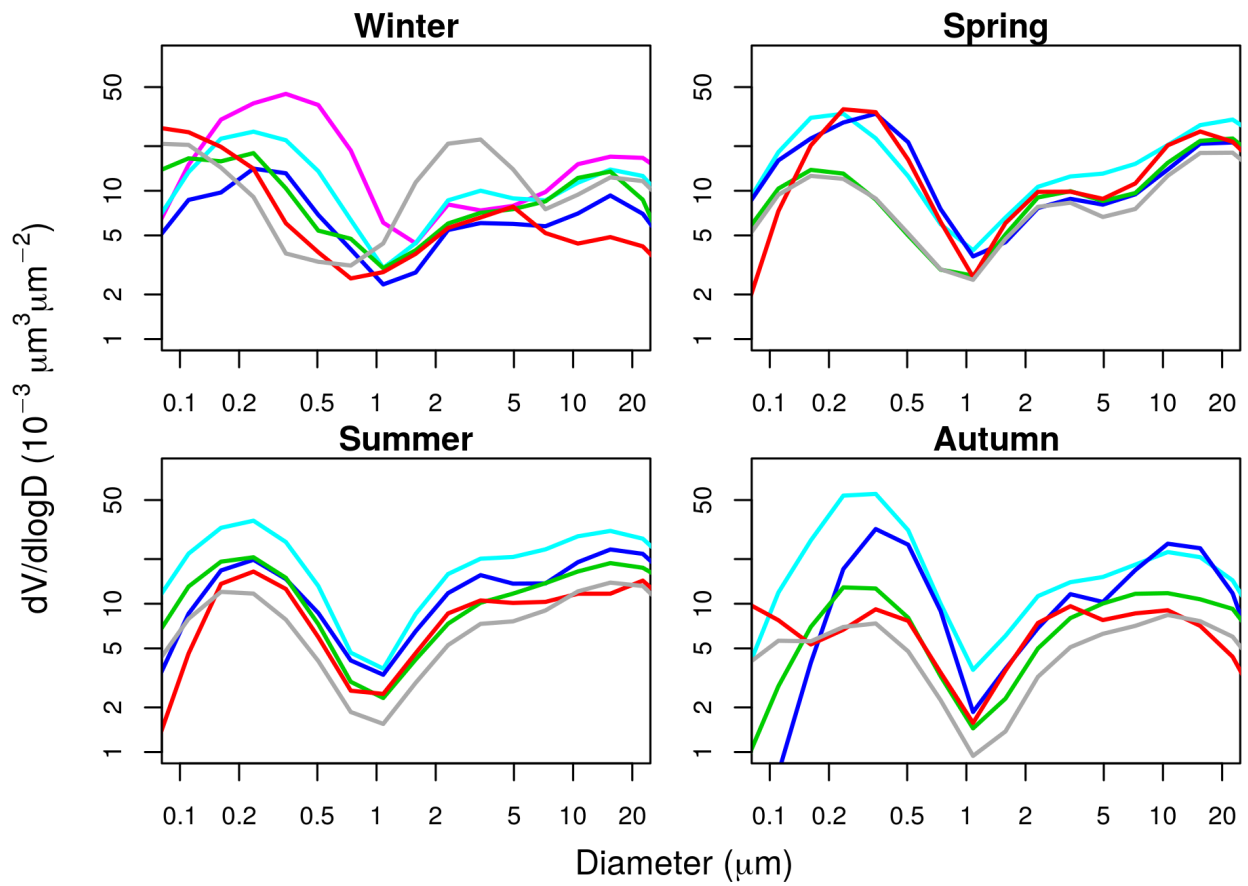

Diameter $(\mu \mathrm{m})$

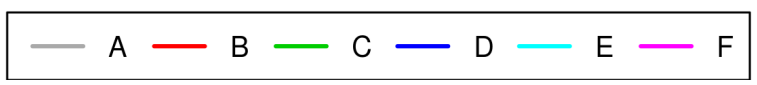

Figure S11: Average (column) particle volume distributions measured by the sun photometer over the Aosta-SaintChristophe station. 


\section{S7 Additional maps from the chemical transport model}

Advection
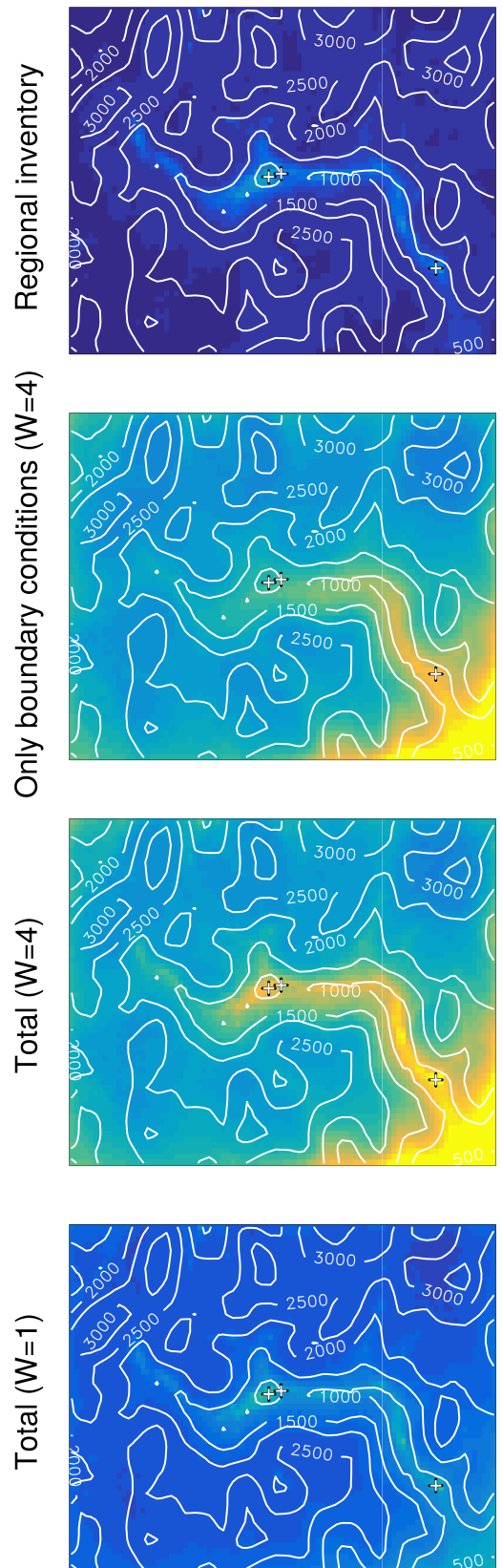

No advection
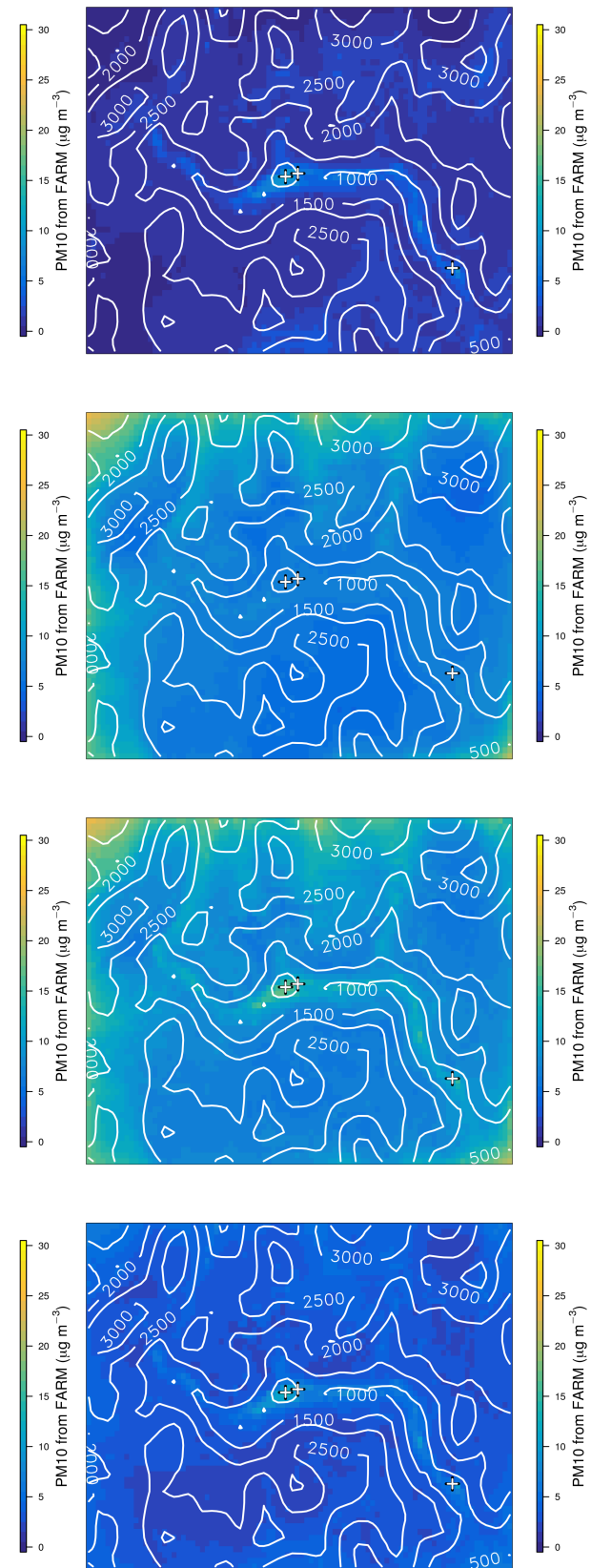

Figure S12: Average maps of $\mathrm{PM}_{10}$ concentrations from FARM. The two columns correspond to advection (left) and non-advection (right) cases as detected by the ALC (day types A and day types $\mathrm{C}, \mathrm{E}$ and $\mathrm{F}$, respectively). The rows corresponds to the contributions of only local $\mathrm{PM}_{10}$ (from inside the regional domain), only outside of the regional domain (this contribution being multiplied by a factor $W=4$ ), and total (using both $W=4$ and $W=1$ ). 


\section{References}

Aiken, A. C., de Foy, B., Wiedinmyer, C., DeCarlo, P. F., Ulbrich, I. M., Wehrli, M. N., Szidat, S., Prevot, A. S. H., Noda, J., Wacker, L., Volkamer, R., Fortner, E., Wang, J., Laskin, A., Shutthanandan, V., Zheng, J., Zhang, R., Paredes-Miranda, G., Arnott, W. P., Molina, L. T., Sosa, G., Querol, X., and Jimenez, J. L.: Mexico city aerosol analysis during MILAGRO using high resolution aerosol mass spectrometry at the urban supersite (T0) - Part 2: Analysis of the biomass burning contribution and the non-fossil carbon fraction, Atmos. Chem. Phys., 10, 5315-5341, doi:10.5194/acp-10-5315-2010, 2010.

Cugerone, K., De Michele, C., Ghezzi, A., Gianelle, V., and Gilardoni, S.: On the functional form of particle number size distributions: influence of particle source and meteorological variables, Atmos. Chem. Phys., 18, 4831-4842, doi:10.5194/acp-18-4831-2018, 2018.

Egger, J., Bajrachaya, S., Egger, U., Heinrich, R., Reuder, J., Shayka, P., Wendt, H., and Wirth, V.: Diurnal Winds in the Himalayan Kali Gandaki Valley. Part I: Observations, Mon. Weather Rev., 128, 1106-1122, doi:10.1175/ 1520-0493(2000)128<1106:DWITHK〉2.0.CO;2, 2000.

EU Commission: Directive 2008/50/EC of the European Parliament and of the Council of 21 May 2008 on ambient air quality and cleaner air for Europe, Official Journal of the European Union, pp. L152/1-44, 2008.

Lufft: Manual Ceilometer CHM 15k NIMBUS, Revision R07, 2016.

Paatero, P., Eberly, S., Brown, S. G., and Norris, G. A.: Methods for estimating uncertainty in factor analytic solutions, Atmos. Meas. Tech., 7, 781-797, doi:10.5194/amt-7-781-2014, 2014.

Urban, R., Lima-Souza, M., Caetano-Silva, L., Queiroz, M., Nogueira, R., Allen, A., Cardoso, A., Held, G., and Campos, M.: Use of levoglucosan, potassium, and water-soluble organic carbon to characterize the origins of biomass-burning aerosols, Atmos. Environ., 61, 562 - 569, doi:10.1016/j.atmosenv.2012.07.082, 2012. 